\title{
Mechanical Properties of Some Epoxy-PMMA Blends
}

\author{
GEORGEL MIHU1 ${ }^{1}$, SEBASTIAN-MARIAN DRAGHICI ${ }^{1}$, VASILE BRIA ${ }^{1,2}$, \\ ADRIAN CIRCIUMARU ${ }^{1,2 *}$, IULIAN-GABRIEL BIRSAN ${ }^{1,2}$
}

${ }^{1}$ Research and Development Center for Thermoset Matrix Composites - CCDCOMT, Dunarea de Jos University of Galati, $111^{\text {th }}$ Domneasca Str., 800008, Galati, Romania

${ }^{2}$ Cross-border Faculty, Dunarea de Jos University of Galati, $111^{\text {th }}$ Domneasca Str., 800008 , Galati, Romania

\begin{abstract}
The thermoset polymers and the thermoplastic polymers matrix composites require different forming techniques due to the different properties of two classes of polymers. While the forming technique for thermoset polymer matrix composites does not require the use of special equipment, the thermoplastic polymer matrix composites imposes the rigorous control of temperature and pressure values. Each type of polymer transfers to the composite a set of properties that may be required for a certain application. It is difficult to design a composite with commonly brittle thermoset polymer matrix showing properties of a viscoelastic thermoplastic polymer matrix composite. One solution may consist in mixing a thermoset and a thermoplastic polymer getting a polymer blend that can be used as matrix to form a composite. This study is about using PMMA solutions to obtain thermoset-thermoplastic blends and to mechanically characterize the obtained materials. Three well known organic solvents were used to obtain the PMMA solutions, based on a previous study concerning with the effect of solvents presence into the epoxy structure.
\end{abstract}

Keyword: epoxy resin, PMMA, organic solvents, tensile tests

\section{Introduction}

The nowadays life is depending more and more on the characteristics of materials that are used to produce high quality goods. In this regard, in automotive industry, it is well known the fact that the use of composites leads to lowering of fossil fuels consumption along with an improvement of its efficiency due to the simple fact that the composites are generally showing lower specific weight. The needs for environmental protection will determine perhaps a huge spreading of composites employment in many applications even they are more expensive than the traditional materials (wood, metal, etc.). However, according to the economic laws, sooner or later, the price of composites will lower once the technologies and raw materials will become cheaper.

The thermoplastic polymers are processed at relatively elevated values of the temperatures and require special equipment with a high level of parameters control in order to obtain quality materials. In this case the raw materials are cheaper and their waste is recyclable - as is the case of polyethylene terephthalate but, not only. The technology - mainly injection molding - to obtain high quality materials refers to the bulk materials and the high control of processing parameters is imposed by the need to avoid the voids into the material volume. To form composites with thermoplastic polymer matrix is more difficult because the presence of a structure (what will become the reinforcement of the composite) inside the mold is increasing the need of parameters control.

On another hand, the thermoset polymers are brittle solids but their formation implies less technology and equipment since they are resulting from chemical reactions of two liquid components (as the simplest method). The thermoset polymer composites are also easy to be formed using the well-known wet lay-up technique that requires only patience and attention from the manufacturer. Of course handling of the reinforcements had been replaced by automat machines what are cutting and placing the materials and even are ensuring the pre-polymer spraying on the surfaces of the reinforcement sheets.

*email: adrian.circiumaru@ugal.ro 
In a prior study we have developed an investigation regarding the possibility to change the basic properties of an epoxy resin using well-known organic solvents (the ones that are used in polymer industry) [1]. It was proven that the presence of various amounts of solvents leads to a plasticization of the epoxy matrix reducing its brittleness but also lowering its strength. Depending on the solvent type and solvent ratio into the matrix even very soft materials were obtained. Along the last decade many studies are concerning with polymer blends especially the ones of a thermoset with a thermoplastic. Often the obtained materials are showing shape memory properties. There are some references dealing with the design of shape memory polymer materials based on the assumption that the mixture of a thermoset polymer and of a thermoplastic polymer leads to a shape memory materials. The properties of such materials are observable in the vicinity of glass transition point of the thermoplastic polymer [2,3].

The advances in nanotechnology and nano-science determined new approaches regarding the shape polymer materials due to their perspectives in medical applications [4-7]. Also, the need for recycling materials marked an important influence on the evolution of shape memory polymers since the engineers and researches tried to promote new ways of waste valorisation. Various theoretical approaches were presented as designing solution regarding the forming technique, the properties and final utilisation of such materials [8-14]

Of course, one important issue is to find the way leading to the mixture between a thermoset polymer and a thermoplastic polymer and in this regard there are some strategies proposed by various researchers [15-19]. As per epoxy resins (as the most versatile thermoset polymers) a review regarding their use in forming shape memory materials is provided in [20]. The use of various solvents is reported in attempts aiming to change the propertis of epoxy resins [21-23], to ensure a higher quality bond between a thermoplastic polymer matrix composite and a thermoset polymer matrix composite [14,24,25].

The polymer blends between a thermoplastic polymer and a thermoset polymer are seen as future path to form nanostructures and there exist some studies regarding this approach [13,26-28]. Other researches are oriented toward finding ways to neutralize the epoxy resins after their normal lifetime due to some interventions that could favour special responses at various external loadings. Since the epoxies are special for many industries increase in their production it is expected and therefore in their waste management [29-32]. Also attention is given to other thermoset polymers [33]. Special attention is also accorded to various interventions that are required to repair composites structures [34].

Present study was designed in order to investigate the effect on mechanical properties of an epoxy resin when it is modified with PMMA solutions. The three solvents effect on mechanical properties of epoxy resins, were studied before and that study represents a starting point regarding control over epoxies brittleness and forming composite plates with graded elasticity across their thickness [35,36].

\section{Materials and methods}

During a previous study the effect of solvents presence inside the epoxy resins was evaluated by mechanically analyzing samples of three different commercial epoxy resins modified with solvents. The three solvents were 1-methyl 2-pyrrolidone, 1,4 dioxane and, N,N dimethylformamide and their presence into the final material was of 10\%(vc). One of the epoxy resins was Epiphen RE4020-DE4020 (where RE4020 is the resin and DE4020 is the hardener) which was also used for the present study. That study revealed that the mechanical properties of the epoxy resin might be controlled by using the solvents (namely reducing the brittleness) without changing the high adhesion of the polymer to other materials. That is why the present study concerning with the mechanical properties of the named epoxy resin when some quantities of PMMA solution in the three solvents are used as modifying agents is connected to the previous study. In order to offer an image regarding the effect of PMMA solution in the Epiphen epoxy system, three reference materials are also presented. These three materials, formed during the previous mentioned study, represent diluted Epiphen epoxy system materials each of them being formed by adding calculated volumes of above listed solvents. The three reference materials are denoted as ME - Epiphen diluted with 10\%(vc) 1-methyl 2-pyrrolidone, DE - Epiphen diluted with 10\%(vc) 1,4 dioxane, and NE - Epiphen diluted with $10 \%$ (vc) N,N dimethylformamide. 
The primary tests regarding the PMMA solubility into the three named solvents were made under normal conditions and the solutions were obtained at the highest achievable concentrations. The highest concentration was obtained in the case of N,N dimethylformamide $(20 \%)$ while for the other two solvents the PMMA solutions the concentration was $15 \%$, where the concentration, in this case, is weight concentration.

Certain amounts of these solutions were mixed with the resin (Epiphen RE4020) in order to form samples with volume concentration of $10 \%, 15 \%$, and $20 \%$ for each solution in the final material. Each mixture of resin and solution was stirred for one hour on a magnetic stirrer in order to ensure a good homogenization. After that, the necessary amount of hardener (DE4020) was added and the new mixture was homogenized for $15 \mathrm{~min}$ by means of a mechanical mixer. The obtained pre-polymer mixture was casted into PPE cylindrical dies of $8 \mathrm{~mm}$ diameter and 200mm height.

The dies containing the modified polymer were kept at normal conditions for seven days so that the polymerization occurred allowing the eventual gaseous emissions through the open end of each die. Finally the dies were removed and the polymer cylinders were thermally consolidated following the next scheme: eight hours at $60^{\circ} \mathrm{C}$, six hours at $80^{\circ} \mathrm{C}$, and two hours at $90^{\circ} \mathrm{C}$. This scheme is recommended by the epoxy system producer to reach the best properties of the epoxy resin (as they are presented in the technical sheet).

The present study is just a part of a larger one containing other thermoplastic polymers, other epoxy systems but the same solvents and that is why the tested materials are named using a four digits system were the first represents the thermoset polymer (PMMA-P), the second represents the solvent (M for 1methyl 2-pyrrolidone, $\mathrm{N}$ for $\mathrm{N}, \mathrm{N}$ dimethylformamide, and $\mathrm{D}$ for 1,4 dioxane), the third represents the epoxy system (in this case Epiphen - E), and the last one, the forth, represents the concentration of thermoplastic polymer solution into the epoxy in the final material ( 1 for 10\%, 2 for 15\%, and 3 for $20 \%)$.

The tensile tests were carried out on an Instron machine on the cylindrical samples, using a pneumatic grip system with the maxim load of $100 \mathrm{kN}$. The BlueHill software allowed determination of some parameters of interest. The tests on the reference materials were made four years ago on standard samples (ASTM D638-03).

\section{Results and discussions}

When the material behavior understanding is intended it is very important to get information about each tested sample. That is because each sample is cut out from a different part of formed material (when the formed material is a plate) or each sample is individually formed. In the first case it is possible to get a concentration gradient depending on die position during polymerization. In the second case because the sample properties depend on the moment of casting due to the fact that, during the casting, the prepolymer gelation is continuous and, of course, there are differences between the first casted sample (lowest viscosity of pre-polymer mixture) and the last casted one (highest viscosity of pre-polymer mixture). In this regard a study effectuated also at CCDCOMT revealed the importance of knowing the position on original material of each cut sample [33]. Of course, in the cited case was about fibre fabric reinforced composite plates and the tensile test results were different for different samples cut out from the same plate.

As it has been mentioned, the diluted Epiphen materials (reference materials) were studied before and the stress/strain curves for analysed sample are presented in Figure 1. It is obvious that, from the mechanical point of view, the 1,4 Dioxane modified materials are the most unstable (large dispersion of experimental results) while the most stable is the N,N dimethylformamide modified material. In the case of DE material the data corresponding to the third sample was removed out when averaged. For each material five samples were tested but for the current presentation just the significant ones were chosen (excepting the case of DE materials where the decision was to present the third sample inclusive).

The PMMA/epoxy materials were formed starting with $10 \%(\mathrm{vc})$ presence of PMMA solution in named solvents (to allow the comparison with the solvent modified epoxy materials) and the presence 
of solution was then increased. In Figure 2. the PMMA/1,4 Dioxane modified epoxy responses at tensile tests are presented. It is not difficult to notice that the material response depends on the modifying agent presence (concentration) both from amplitude point of view and from the response uniformity point of view. The most stable response (the lowest dispersion of individual curves) appears for the highest concentration and, in this case it is normal to reason that the solvent concentration is important. Continuing the presentation, the results for PMMA/1-methyl 2-pyrrolidone and PMMA/N,N dimethylformamide are presented in Figure 3 and Figure 4. It seems that increasing the solvent amount the materials response if more uniform. During the mechanical tests it was noticed a tendency of super elasticity (in fact, it was noticed that during those tests even the gripped parts of the samples were engaged and because of diameter reduction they were released form grips). At the end, all the samples recovered initial form. Also, it has to be noticed that the modified materials response evolved from brittle (lowest concentrations) to visco-elastic behaviour (higher concentrations).
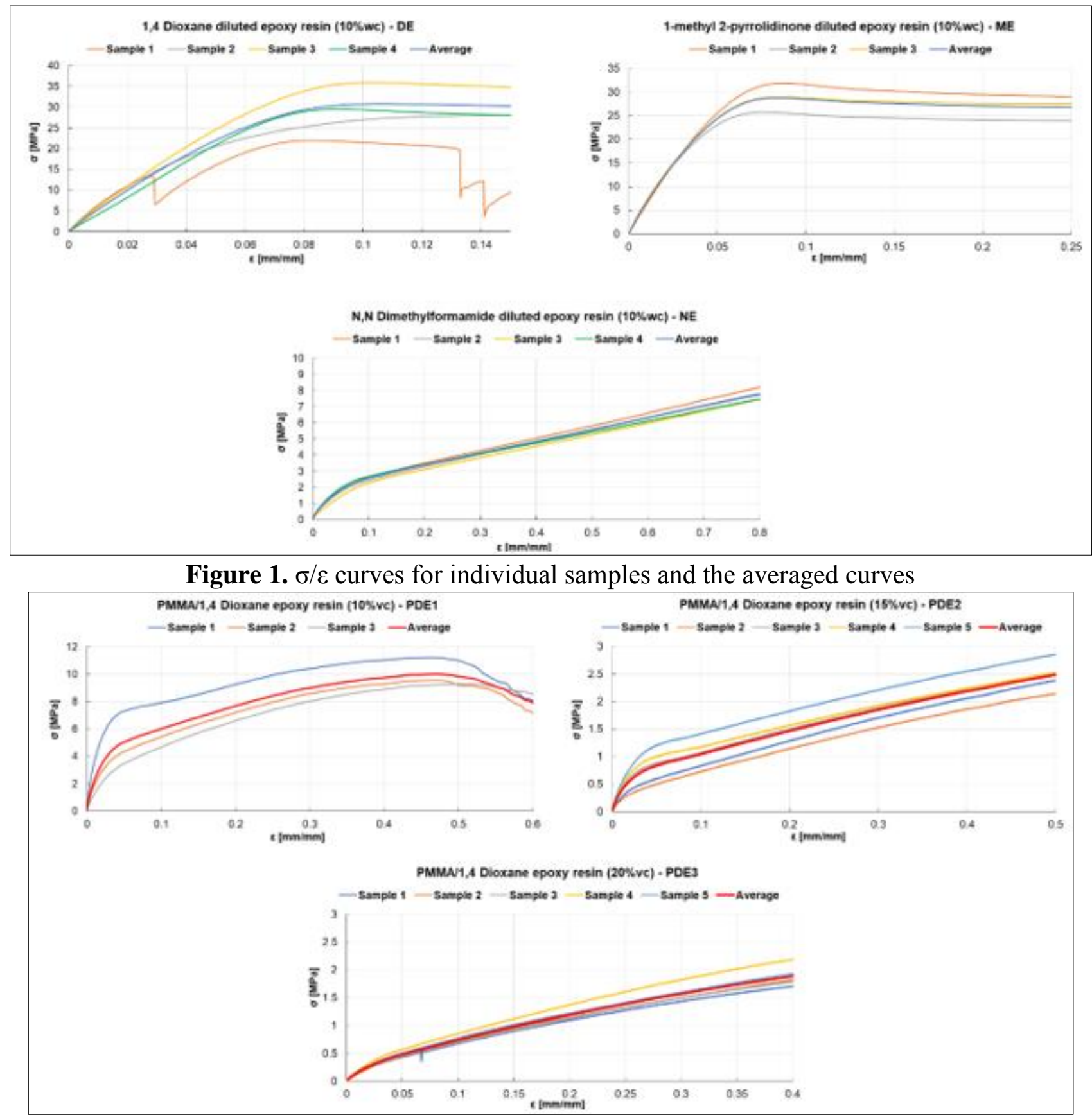

Figure 2. $\sigma / \varepsilon$ curves for PMMA/1,4 Dioxane modified epoxy materials 


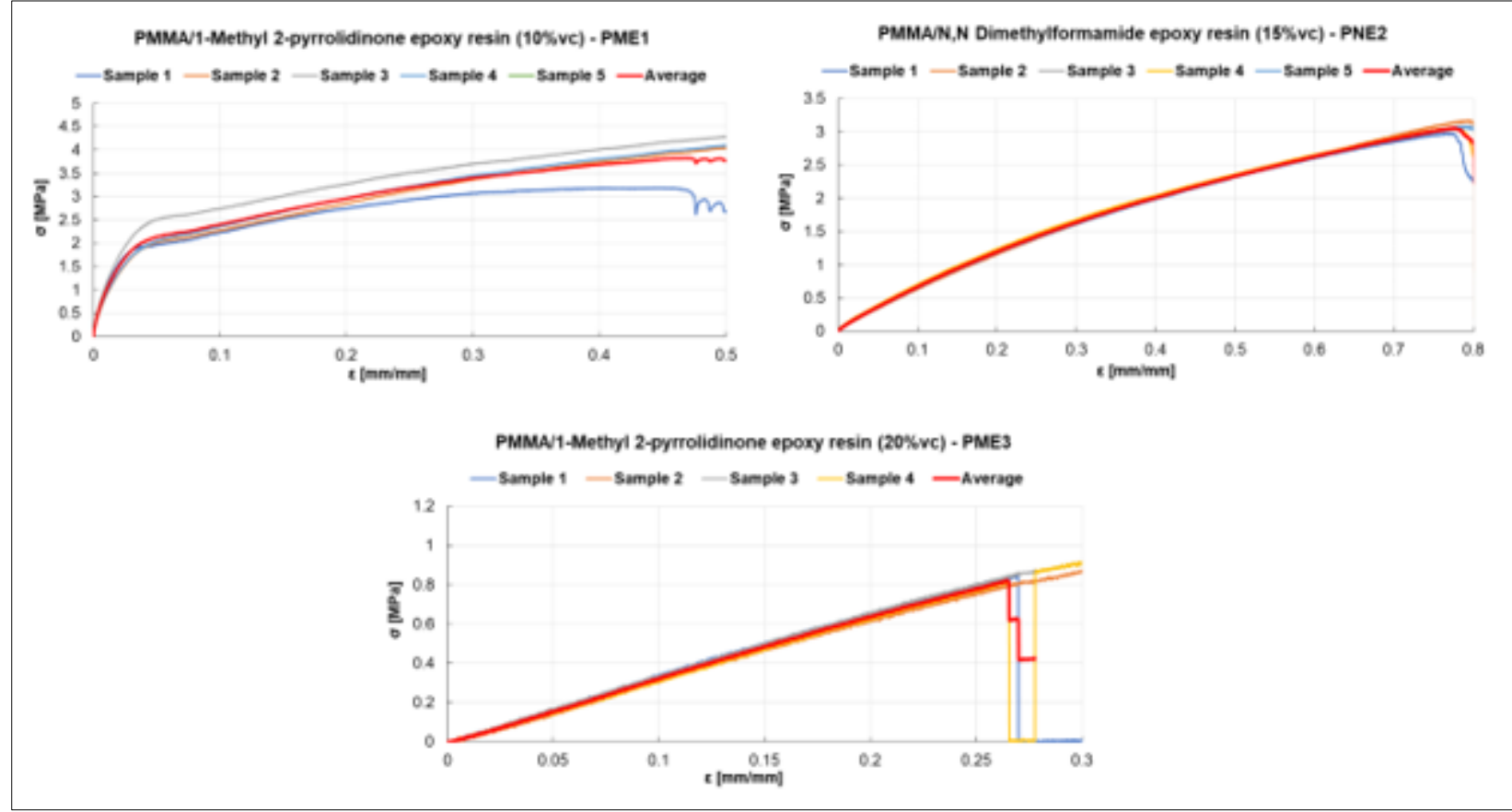

Figure 3. $\sigma / \varepsilon$ curves for PMMA/1-methyl 2-pyrrolidinone modified epoxy materials

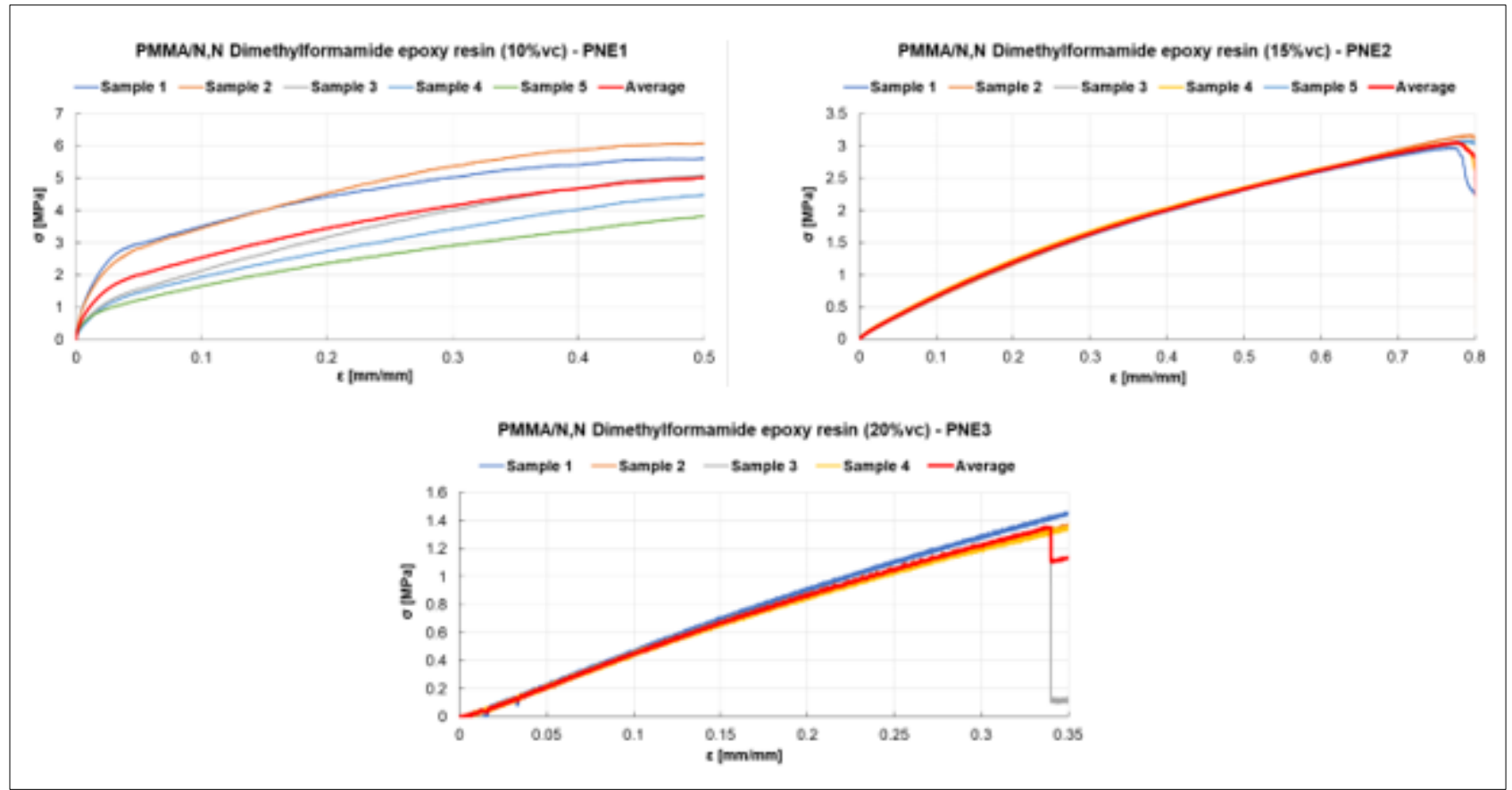

Figure 4. $\sigma / \varepsilon$ curves for PMMA/N, N Dimethylformamide modified epoxy materials

Perhaps, a better image could be formed analysing the curves in Figure 5. These curves are composed considering the DE, ME and, NE materials as references to compare the PMMA/respective solvents averaged responses of materials. It seems that the presence of the PMMA repairs some damages induced by the solvent presence. The effect is major in the case of 1,4 Dioxane but it is also important in the case of the other two solvents for the lowest concentration of PMMA/solvent into the epoxy resin. At concentrations over 10\% the effect of PMMA/solvent solution is damaging the material response but, of course, with different importance.

During the mechanical tests a software application is controlling the machine and it is able to provide some interesting parameters. In this case the elastic modulus value was set as output parameter. The 
software application is not programmed to recognize a critical moment as elastic limit, for instance, if the changes are not too high, therefore the earliest response, coincides with the ultimate response during the automatic analysis. In Figure 6 the values of elastic modulus are presented as they are automatically evaluated during tests. As expected the solvent presence into the epoxy resin lowers the elastic modulus value of the polymer (evaluated at $2.83 \mathrm{GPa}$ ) as all the three solvents act as plasticizers. All the materials obtained by epoxy modification with PMMA solutions are formed at 10\%, 15\%, 20\%(vc). One conclusion is obvious - the PMMA presence in the epoxy resin (via solution) at $10 \%$ (vc) leads to an increase of the elastic modulus value with respect to the solvent modified epoxy. The highest increase is in the case of N, N Dimethylformamide and the lowest in the case of 1-Methyl 2-pyrrolidinone.

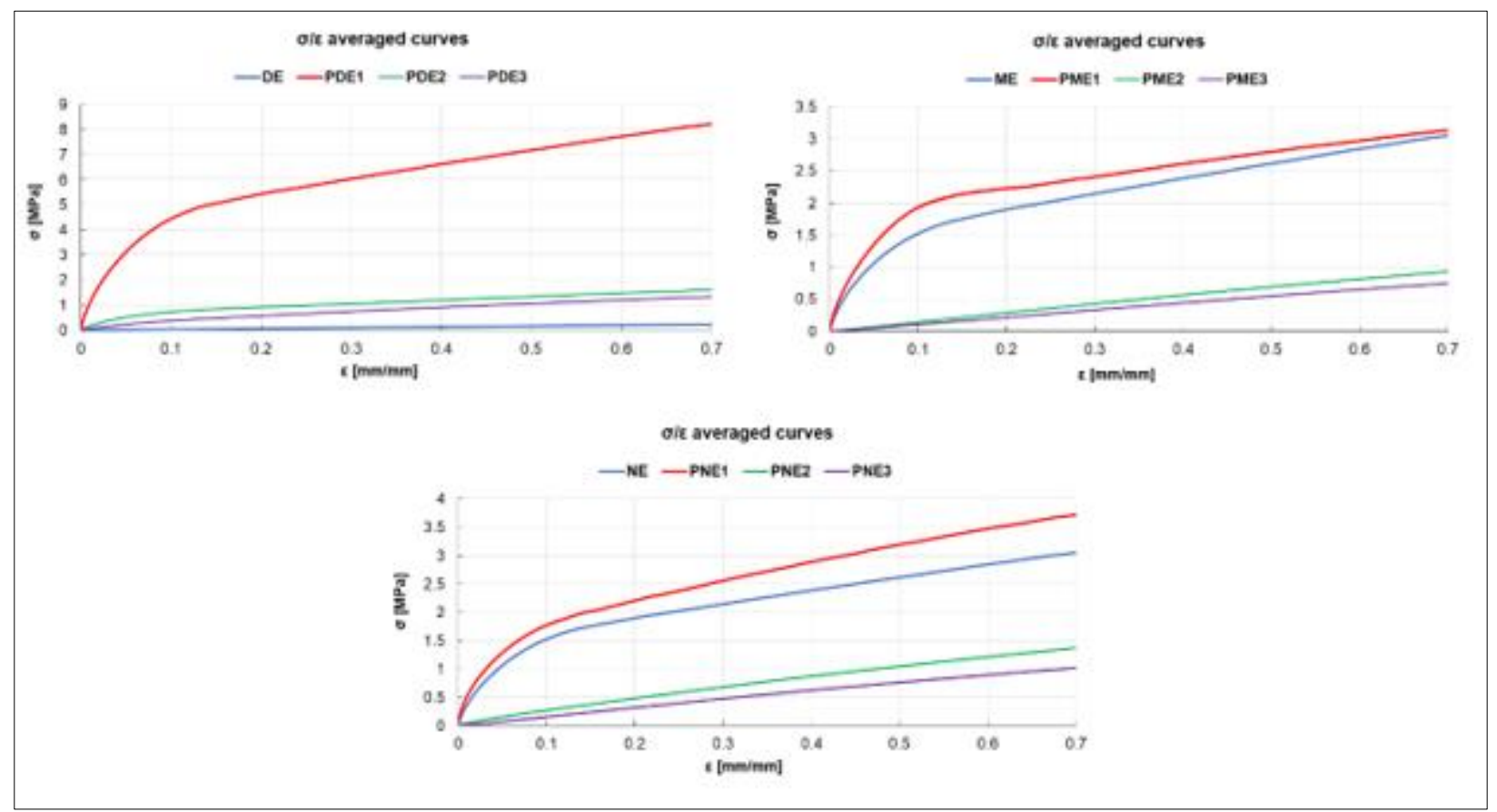

Figure 5. Averaged $\sigma / \varepsilon$ curves for studied materials

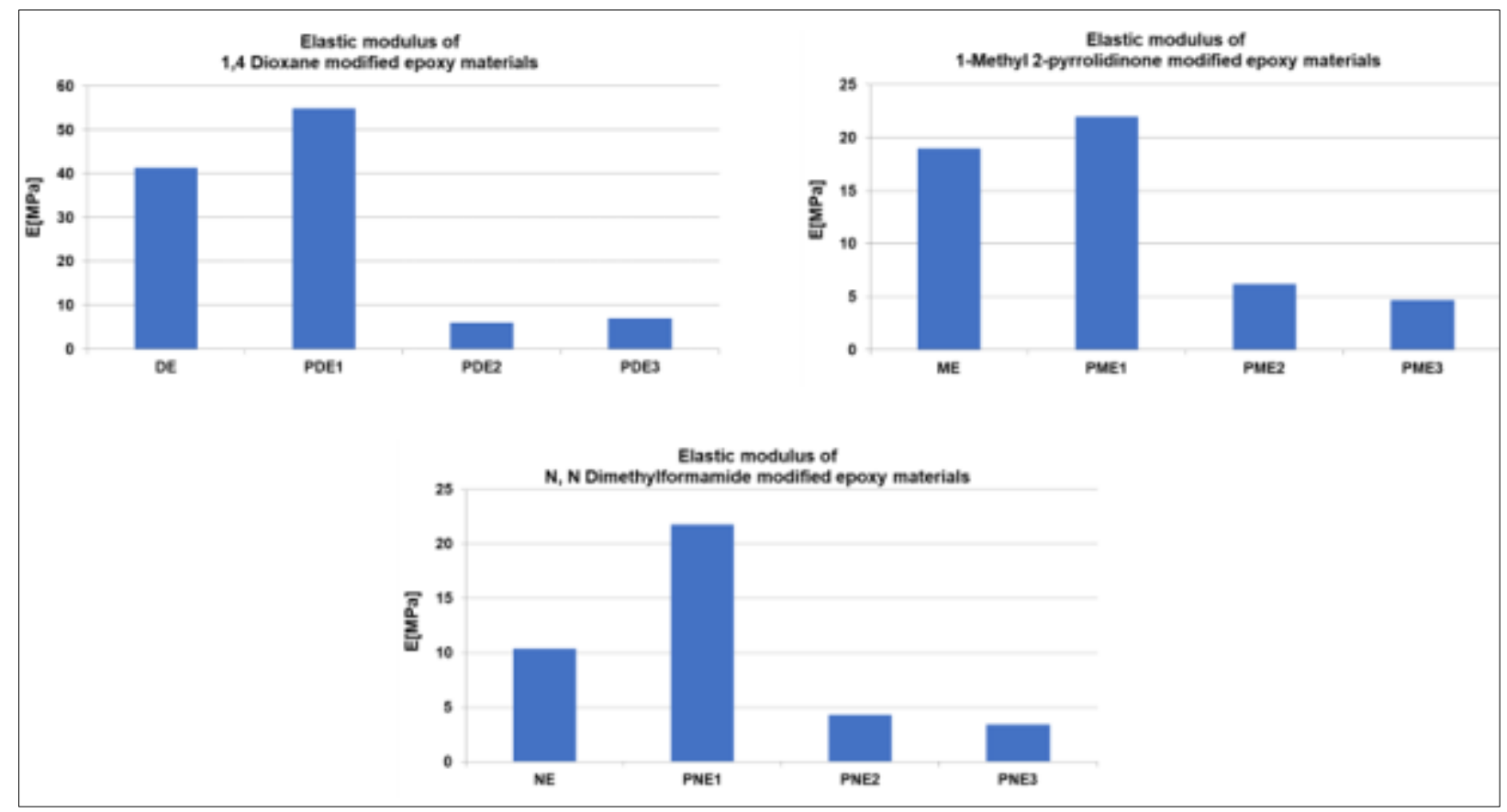

Figure 6. Elastic modulus of modified epoxy materials 


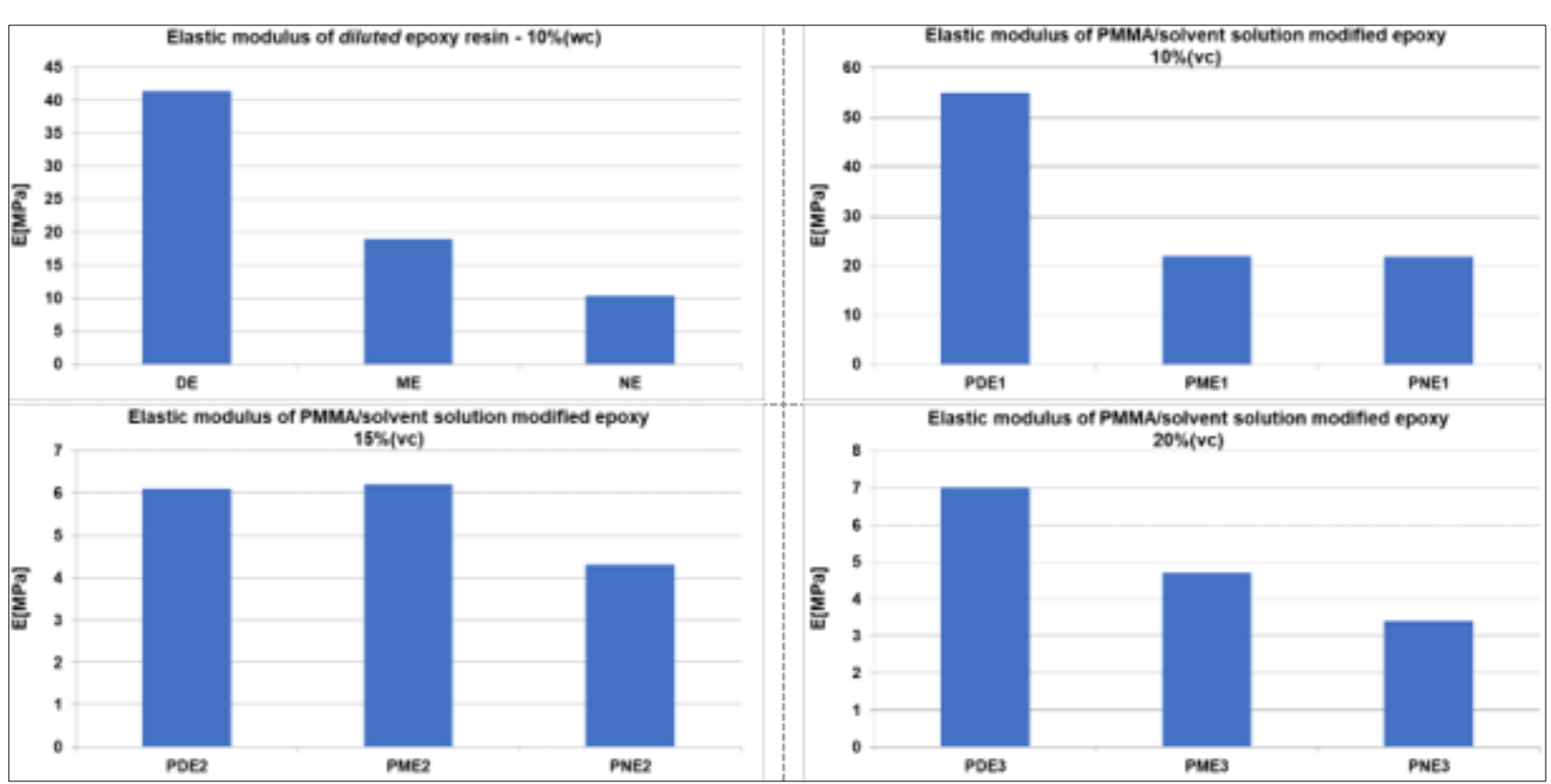

Figure 7. Comparative analysis of elastic modulus values

As expected, for all the solvents, the rise in solution concentrations leads to lowering of the elastic modulus values. A significant aspect is presented in Figure 7 and is about a comparative analysis regarding the elastic modulus values of formed materials at the same amount of modifying agent. N, N Dimethylformamide and PMMA/N, N Dimethylformamide solutions lead to materials with the lowest values of elastic modulus while 1,4 Dioxane and PMMA/1,4 Dioxane solutions lead to materials with the highest values of elastic modulus with respect to epoxy resin.

Such materials could be used as intermediate matrix for fabric reinforced materials because their presence reduces the epoxy brittleness protecting the reinforcement for sharing failure when the epoxy matrix is fractured at various impact mechanisms.

\section{Conclusions}

This study was designed to investigate the effect of PMMA solutions (in three different solvents) on the mechanical properties of an epoxy resin. Due to other studies the properties of the mentioned epoxy resins are known and also it is known the effect of solvents on the resin mechanical properties. The three solvents are 1,4 Dioxane, 1-Methyl 2-pyrrolidinone and, N, N Dimethylformamide and all of them have a plasticizing effect on epoxy resin meaning that mechanical behaviour changed from brittle to elasticplastic.

Al the materials modified with PMMA solution at $10 \%, 15 \%$ and, $20 \%$ (vc) show memory shape behaviour. More than that, it was noticed that during tests even the gripped part of samples was engaged such as the sample was released from de grips and recovered their initial form.

For further studies an analysis regarding the effect of such solutions have to be done for a more fine scale of concentrations together, perhaps, with other thermoplastic polymers solutions. This approach is not unknown since there are published studies regarding memory shape materials obtained from thermoset-thermoplastic blends and also studies regarding the vitrimers as a solution to thermosets neutralization.

\section{References}

1.CIUBOTARIU OANA-ROXANA, BRIA V, GRAUR, VIONESCU DOINA. Electric Conductivity of Modified Epoxies. Rev Chim, 66(11), 2015, 1903-1906. 
2.ZOU F, CHEN S. A NOVEL 2,6-Diaminopyridine-base Polymer with Thermo-/Water-responsive Shape Memory Effect. Mater Today Proc 16, 2019, pp.1548-1553.

https://doi.org/10.1016/j.matpr.2019.05.339.

3.XIAO R. Modeling shape-memory effects in amorphous polymers. Mater Today Proc 16, 2019, pp. 1462-1468. https://doi.org/10.1016/j.matpr.2019.05.324.

4.ZHAO W, LIU L, ZHANG F, LENG J, LIU Y. Shape memory polymers and their composites in biomedical applications. Mater Sci Eng, 97, 2019, pp. 864-883.

https://doi.org/10.1016/j.msec.2018.12.054.

5.HUANG J, FAN J, YIN S, CHEN Y. Design of remotely, locally triggered shape-memory materials based on bicontinuous polylactide/epoxidized natural rubber thermoplastic vulcanizates via regulating the distribution of ferroferric oxide. Compos Sci Technol, 182, 2019, 107732.

https://doi.org/10.1016/j.compscitech.2019.107732.

6.BAI Y, ZHANG J, WEN D, GONG P, LIU J, JU J, et al. A reconfigurable, self-healing and near infrared light responsive thermoset shape memory polymer. Compos Sci Technol, 187, 2020, 107940. https://doi.org/10.1016/j.compscitech.2019.107940.

7.ZHANG X, GEVEN MA, GRIJPMA DW, PEIJS T, GAUTROT JE. Tunable and processable shape memory composites based on degradable polymers. Polymer, 122, 2017, pp. 323-331.

https://doi.org/10.1016/j.polymer.2017.06.066.

8.ZHENG Y, JI X, SHEN J, GUO S. Tunable Shape Memory Capacity of Polymeric Materials via Multilayer-Assembled Strategy. Mater Today Proc, 16, 2019, pp. 1410-1414, https://doi.org/10.1016/j.matpr.2019.05.316.

9.GU L, JIANG Y, HU J. Structure Design and Property of Spider silk-Inspired Shape Memory Materials. Mater Today Proc, 16, 2019, pp.1491-1496. https://doi.org/10.1016/j.matpr.2019.05.329.

10.LIU T, LIU L, YU M, LI Q, ZENG C, Lan X, et al. Integrative hinge based on shape memory polymer composites: Material, design, properties and application. Compos Struct, 206, 2018; pp.164-176. https://doi.org/10.1016/j.compstruct.2018.08.041.

11.ZHAO H, LAN X, LIU L, LIU Y, LENG J. Design and analysis of shockless smart releasing device based on shape memory polymer composites. Compos Struct, 223, 2019, 110958.

https://doi.org/10.1016/j.compstruct.2019.110958.

12.ABAVISANI I, REZAIFAR O, KHEYRODDIN A. Multifunctional properties of shape memory materials in civil engineering applications: A state-of-the-art review. J Buid Eng, 44, 2021, 102657. https://doi.org/10.1016/j.jobe.2021.102657.

13.DU H, LIU L, ZHANG F, ZHAUO W, LENG J, LIU Y. Thermal-mechanical behavior of styrenebased shape memory polymer tubes. Polym Test, 57, 2017, pp.119-125.

https://doi.org/10.1016/j.polymertesting.2016.11.011.

14.XIE H, LI L, DENG X-Y, CHENG C-Y, YANG K-K, WANG Y-Z. Reinforcement of shape-memory poly(ethylene-co-vinyl acetate) by carbon fibre to access robust recovery capability under resistant condition. Compos Sci Technol, 157, 2018, pp.202-208.

https://doi.org/10.1016/j.compscitech.2018.01.031.

15.GU L, JANG Y, HU J. Bioinspired poly(vinyl alcohol)-silk hybrids: Two-way water-sensitive shapememory materials. Mater Today, 17, 2018, pp.419-426. https://doi.org/10.1016/j.mtcomm.2018.10.005. 16.YANG K, DU J, ZHANG Z, REN T. A facile strategy to fabricate robust triple-shape memory polymer. Mater Lett, 257, 2019, 126753. https://doi.org/10.1016/j.matlet.2019.126753.

17.LI W, LIU Y, LENG J. Light-actuated reversible shape memory effect of a polymer composite. Compos Part A-Appl S, 110, 2018, pp.70-75. https://doi.org/10.1016/j.compositesa.2018.04.019.

18.MARTINS GS, PEREIRA IM, OREFICE RL. Toughening brittle polymers with shape memory polymers. Polymer, 135, 2018, pp.30-38. https://doi.org/10.1016/j.polymer.2017.12.017.

19.KONG D, LI J, GUO A, ZHANG X, XIAO X. Self-healing high temperature shape memory polymer. Eur Polym J, 120, 2019,109279. https://doi.org/10.1016/j.eurpolymj.2019.109279. 
20.KUMAR PATEL K, PUROHIT R. Future Prospects of shape memory polymer nano-composite and epoxy based shape memory polymer- A review. Mater Today Proc, 5 2018, pp.20193-20200. https://doi.org/10.1016/j.matpr.2018.06.389.

21.RANGANATHA SWAMY MK, MALLIKARJUN US, UDAYAKUMAR V. Shape Memory Polymers Synthesised For Controllable Switching Temperatures. Mater Today Proc, 4, 2017, pp.1114811153. https://doi.org/10.1016/j.matpr.2017.08.079.

22.BUI R, BROOK MA. Dynamic covalent Schiff-base silicone polymers and elastomers. Polymer, 160, 2019, pp.282-290. https://doi.org/10.1016/j.polymer.2018.11.043.

23.G. MIHU, I. MIHALACHE, M. BODOR, O. MIRCEA, IULIA GRAUR. Tribological Characterization of Modified Epoxy Systems. Mater Plast, 2, 2016, pp.298-303.

24.TENG J, WANG Z, LIU J, SUN X. Thermodynamic and shape memory properties of TPI/HDPE hybrid shape memory polymer. Polym Test, 81, 2020, 106257.

https://doi.org/10.1016/j.polymertesting.2019.106257.

25.ZHAO W, LIU L, LENG J, LIU Y. Thermo-mechanical behavior prediction of shape memory polymer based on the multiplicative decomposition of the deformation gradient. Mech Mater, 143, 2020, 103263. https://doi.org/10.1016/j.mechmat.2019.103263.

26.FANG C, LENG J, SUN H, GU J. A multi-branch thermoviscoelastic model based on fractional derivatives for free recovery behaviors of shape memory polymers. Mech Mater, 120, 2018, pp.34-42. https://doi.org/10.1016/j.mechmat.2018.03.002.

27.CHERKASHINA NI, PAVLENKO VI, POPOVA EV, SIROTA VV, GORODOV AI. PI/WO 2 composite with two layers of reinforcement of carbon fabric. Polym-Plast Technol Mater, 59, 2020, pp.1574-1584. https://doi.org/10.1080/25740881.2020.1757107.

28.GOROVEI CLAUDIA-MIHAELA, CEOROMILA ALINA-MIHAELA, V. BRIA, CÎRCIUMARU A, BIRSAN IG. Inorganic Agents Modified Epoxy Resin. Mater Plast, 58(2) 2021, pp.71-79. https://doi.org/doi.org/10.37358/Mat.Plast.1964.

9.LORKE S, MULLER U, MEISSL R, BRUGGEMANN O. Covalent cross-linking of polymers at room temperature. Int J Adhes Adhes, 91, 2019, pp.150-159. https://doi.org/10.1016/j.ijadhadh.2019.03.011. 30.ZARE M, PRABHAKARAN MP, PARVIN N, RAMAKRISHNA S. Thermally-induced two-way shape memory polymers: Mechanisms, structures, and applications. Chem Eng J, 374, 2019, 706-720. https://doi.org/10.1016/j.cej.2019.05.167.

31.WANG C, ZHANG Y, LI J, YANG Z, WANG Q, WANG T, et al. Shape memory properties of interpenetrating polymer networks (IPNs) based on hyperbranched polyurethane (HBPU). Eur Polym J, 123, 2020, 109393. https://doi.org/10.1016/j.eurpolymj.2019.109393.

32.LIU T, ZHOU T, YAO Y, ZHANG F, LIU L, LIU Y, et al. Stimulus methods of multi-functional shape memory polymer nanocomposites: A review. Compos Part A-Appl S, 100, 2017, pp.20-30. https://doi.org/10.1016/j.compositesa.2017.04.022.

33.WANG X, LU H, SHI X, YU K, FU YQ. A thermomechanical model of multi-shape memory effect for amorphous polymer with tunable segment compositions. Compos Part B Eng, 160, 2019, pp.298305. https://doi.org/10.1016/j.compositesb.2018.10.048.

34.ZHOU D, WANG Y, ZHU J, YU J, HU Z. Mechanically strong and highly efficient healable organic/inorganic hybrid dynamic network. Polymer, 167, 2019, pp.202-208.

https://doi.org/10.1016/j.polymer.2019.02.018.

35.BOSOANCA R, BRIA V, MEREUTA C, CIRCIUMARU A, BIRSAN IG. Tensile Analysis of Fabric Reinforced Materials, Mater Plast, 54(4), 2019, 705-714.

36.DIMOFTE M, BUNEA M, CAPATINA A, COJAN A, BOSOANCA R, CIRCIUMARU A. Tensile and Bending Analysis of Fabric Reinforced Graded Epoxy Composites. Mater Plast, 54, 2017, pp.362367. https://doi.org/10.37358/MP.17.2.4852.

$\overline{\text { Manuscript received: } 19.03 .2021}$ 